\title{
A Phase I and Pharmacologic Study of Weekly Gemcitabine in Combination with Infusional 5-fluorodeoxyuridine and Oral Calcium Leucovorin
}

\author{
Jean L. Grem \\ National Cancer Institute-Navy Medical Oncology \\ Mary G. Quinn \\ National Cancer Institute-Navy Medical Oncology \\ Bruce Keith \\ National Cancer Institute-Navy Medical Oncology \\ Brian P. Monahan \\ National Naval Medical Center \\ J. Michael Hamilton

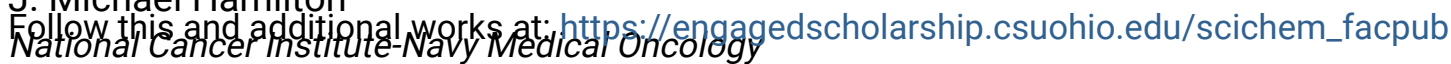 \\ Part of the Chemistry Commons \\ How does access to this work benefit you? Let us know! \\ See pext page for additional authors \\ Publisher's Statement
}

The final publication is available at Springer via http://dx.doi.org/10.1007/s00280-003-0698-5

\section{Recommended Citation}

Grem, Jean L.; Quinn, Mary G.; Keith, Bruce; Monahan, Brian P.; Hamilton, J. Michael; Xu, Yan; Harold, Nancy; Nguyen, Dat; Takimoto, Chris H.; Rowedder, Anthony; Pang, Janet; Morrison, Geraldine; and Chen, Alice, "A Phase I and Pharmacologic Study of Weekly Gemcitabine in Combination with Infusional 5-fluorodeoxyuridine and Oral Calcium Leucovorin" (2003). Chemistry Faculty Publications. 167. https://engagedscholarship.csuohio.edu/scichem_facpub/167

This Article is brought to you for free and open access by the Chemistry Department at EngagedScholarship@CSU. It has been accepted for inclusion in Chemistry Faculty Publications by an authorized administrator of EngagedScholarship@CSU. For more information, please contact library.es@csuohio.edu. 


\section{Authors}

Jean L. Grem, Mary G. Quinn, Bruce Keith, Brian P. Monahan, J. Michael Hamilton, Yan Xu, Nancy Harold, Dat Nguyen, Chris H. Takimoto, Anthony Rowedder, Janet Pang, Geraldine Morrison, and Alice Chen 
Jean L. Grem Mary G. Quinn Bruce Keith

Brian P. Monahan J. Michael Hamilton Yan Xu

Nancy Harold Dat Nguyen Chris H. Takimoto

Anthony Rowedder Janet Pang

Geraldine Morrison Alice Chen

\section{A phase I and pharmacologic study of weekly gemcitabine in combination with infusional 5-fluorodeoxyuridine and oral calcium leucovorin}

\begin{abstract}
Purpose: Since preclinical studies have shown more than additive cytotoxicity and DNA damage with the combination of gemcitabine and 5-fluoro-2'-deoxyuridine (FUDR), we studied this combination in a phase I trial. Methods: Gemcitabine alone was given in cycle 1 as a 24-h, 2-h or 1-h i.v. infusion weekly for 3 of 4 weeks; if tolerated, a 24-h i.v. infusion of FUDR was added with oral leucovorin. The cycle was aborted for grade 3 thrombocytopenia, grade 4 neutropenia, and grade 2 or worse nonhematologic toxicity. Results: During cycle 1 , six of eight patients who received 150 or $100 \mathrm{mg} / \mathrm{m}^{2}$ over $24 \mathrm{~h}$ had dose-limiting neutropenia, thrombocytopenia, fatigue or mucositis. Six of seven patients treated with $1000 \mathrm{mg} / \mathrm{m}^{2}$ over $2 \mathrm{~h}$ required a gemcitabine dose reduction for cycle 2 (thrombocytopenia, neutropenia, fatigue). Of 25 assessable patients who received gemcitabine $1000 \mathrm{mg} / \mathrm{m}^{2}$ over $1 \mathrm{~h}, 7 \mathrm{did}$ not complete cycle 1 due to thrombocytopenia $(n=6)$ or diarrhea $(n=1)$. Of 42 patients entered, 27 received at least one course of gemcitabine/FUDR $\left(5-19.5 \mathrm{mg} / \mathrm{m}^{2}\right.$ over $24 \mathrm{~h}$ ) without appreciable toxicity. Due to a shortage of FUDR, the protocol was closed early. Gemcitabine plasma concentrations averaged $0.061 \mu M$ (24 h), $16.3 \mu M(2 \mathrm{~h})$, and $31.9 \mu M(1 \mathrm{~h})$. In 21 paired bone marrow mononuclear cell samples obtained before treatment and during FUDR infusion, thymidylate synthase ternary complex was only seen during FUDR infusion. Conclusions: Gemcitabine $100-150 \mathrm{mg} / \mathrm{m}^{2}$ over $24 \mathrm{~h}$ was poorly tolerated, whereas toxicity was acceptable with $800-1000 \mathrm{mg} / \mathrm{m}^{2}$ over $1 \mathrm{~h}$. Inhibition of the target enzyme was demonstrated at all FUDR doses.
\end{abstract}

Keywords Pharmacokinetics P Pharmacodynamics . Antimetabolites

\section{Introduction}

Gemcitabine $\left(2^{\prime}, 2^{\prime}\right.$-difluorodeoxycytidine, dFdC, Gemzar; Eli Lilly, Indianapolis, Ind.) is a pyrimidine analog of deoxycytidine that is phosphorylated to its active diphosphate (dFdCDP) and triphosphate (dFdCTP) forms [1]. The initial conversion to the monophosphate form (dFdCMP) by deoxycytidine kinase is rate limiting. $\mathrm{dFdCDP}$ inhibits ribonucleotide reductase resulting in depletion of the deoxynucleotides needed for synthesis and repair of DNA. dFdCTP is incorporated into DNA and acts as a chain terminator in DNA synthesis. $\mathrm{dFdC}$ is deaminated to an inactive metabolite, 2',2'-difluorodeoxyuridine ( $\mathrm{dFdU})$, by cytidine deaminase. Clinically, gemcitabine is used to treat a variety of solid tumors, and the most common method of administration is as a weekly 30-min infusion of $1000 \mathrm{mg} / \mathrm{m}^{2}$.

5-Fluoro-2'-deoxyuridine (FUDR), the deoxyribonucleoside derivative of fluorouracil (5-FU), undergoes 
intracellular metabolism to 5'-fluorodeoxyuridine monophosphate (FdUMP). In the presence of 5,10methylenetetrahydrofolate, FdUMP forms a covalent complex with thymidylate synthase (TS), resulting in depletion of thymidine triphosphate (dTTP) and interference with DNA synthesis and repair [2]. Leucovorin $(\mathrm{LV})$ is used to increase the reduced folate pools and increase the stability of the ternary complex. The ribo- and deoxyribonucleotide triphosphate derivatives of 5-FU are incorporated into RNA and DNA, respectively, interfering with their function. However, fluorouridine triphosphate formation in vitro does not generally occur with FUDR exposure, thus providing more selective inhibition of TS.

There is evidence supporting the combined use of deoxycytidine analogs such as gemcitabine and fluoropyrimidines. In clonogenic studies, exposure to cytarabine, which shares the same metabolic pathways as gemcitabine, for $24 \mathrm{~h}$ prior to the 5-FU resulted in cytotoxicity that was at least additive, while the reverse sequence resulted in marked antagonism [3]. The DNA synthetic inhibition imposed by 5-FU significantly decreased cytarabine incorporation into DNA, thus accounting for the sequence-dependant antagonism. In HT-29 human colon cancer cells, sequential exposure to gemcitabine $(4 \mathrm{~h})$ followed by FUDR $(24 \mathrm{~h})$ resulted in more than additive cytotoxicity and enhanced DNA fragmentation [4]. Further, some patients with pancreatic cancer refractory to 5-FU may still benefit from gemcitabine, suggesting lack of cross resistance [5].

In preclinical studies, the concentration of gemcitabine required for the same degree of growth inhibition is considerably less with prolonged exposure [6]. In vivo models also suggest that prolonged gemcitabine infusions provide better results than bolus injections [7]. Since the plasma half-life of gemcitabine in patients is brief and the formation of dFdCMP is saturable [8,9], continuous infusion offers theoretical advantages over the typical 30-min infusion. Clinical evidence indicates that continuous infusion of 5-FU is associated with a better toxicity profile and better efficacy than bolus administration $[10,11,12,13]$.

We therefore conducted a phase 1 trial involving gemcitabine, FUDR and LV. Initially, gemcitabine was given as a 24-h infusion weekly for 3 of 4 weeks. The starting dose of $150 \mathrm{mg} / \mathrm{m}^{2}$ was selected on the basis of the recommended dose of $180 \mathrm{mg} / \mathrm{m}^{2}$ found in a prior trial [14]. We planned to add FUDR as a 24-h infusion starting after each gemcitabine dose cycle 2; low-dose oral LV was given for 2 days starting 1 day prior to FUDR on each treatment week. Since the toxicity was unexpectedly severe, the duration of the gemcitabine infusion was sequentially shorted to $2 \mathrm{~h}$ and then $1 \mathrm{~h}$ with a starting dose of $1000 \mathrm{mg} / \mathrm{m}^{2}$. The clinical results, achieved plasma concentrations of gemcitabine and $\mathrm{dFdU}$, and assessment of TS ternary complex formation during gemcitabine and FUDR therapy are reported here.

\section{Patients and methods}

\section{Eligibility criteria}

Patients 18 years of age or older with solid tumors who had failed standard therapy for their disease or for whom no such therapy was available were eligible for this trial provided their perfor mance status was 02 , the patient had recovered from prior therapies, the absolute granulocyte and platelet counts were $>2000 / \mu \mathrm{l}$ and $\geq 100,000 / \mu \mathrm{l}$, respectively, and the serum bilirubin and creatinine were $\leq 2.0 \mathrm{mg} / \mathrm{dl}$. Exclusion criteria included dis ease progression on prior gemcitabine, pregnant or nursing wo men, serious concurrent illness which would jeopardize the ability to receive the protocol treatment, active infections, and primary or secondary central nervous system malignancies. This study had the approval of the local Institutional Review Boards and the Cancer Therapy Evaluation Program, National Cancer Institute (NCI). All patients gave written informed consent.

\section{Treatment plan}

Gemcitabine hydrochloride was supplied by the Cancer Therapy Evaluation Program, Division of Cancer Treatment and Diagno sis, NCI (Bethesda, Md.). Sterile FUDR was purchased from Roche Laboratories (Nutley, N.J.). Therapy was administered in the outpatient setting. Prophylactic antiemetics or other classes of premedication were not employed. To ensure its tolerability, gemcitabine was given alone for the initial cycle weekly for 3 of 4 weeks at a starting dose of $150 \mathrm{mg} / \mathrm{m}^{2}$ over $24 \mathrm{~h}$. Due to unto ward clinical toxicity, the protocol was amended to change the dose and duration of gemcitabine to $1000 \mathrm{mg} / \mathrm{m}^{2}$ given over either $2 \mathrm{~h}$ or $1 \mathrm{~h}$. The cycle was to be terminated early and considered complete for a platelet count $<50,000 / \mu \mathrm{l}$, a granulocyte count $<500 / \mu 1$, grade 2 or worse nonhematologic toxicity (excluding nausea/vomiting) prior to week 3 dosing. If all three doses were given, the gemcitabine dose was to be decreased one dose level if the patient had grade 2 or worse nonhematologic toxicity, grade 3 hematologic toxicity, or required a delay of 1 week to permit resolution of toxicity. The gemcitabine dose was decreased two dose levels if the patient could not receive all three planned doses, or for those patients who experienced grade 3 or worse nonhe matologic or grade 4 hematologic toxicity, and in those who required a delay of 2 weeks or more for resolution of toxicity. If a gemcitabine dose reduction was required, the patient received a second cycle of gemcitabine alone. FUDR was subsequently given following each gemcitabine dose at a starting dose of $5 \mathrm{mg} / \mathrm{m}^{2}$ over $24 \mathrm{~h}$. Oral leucovorin $20 \mathrm{mg} / \mathrm{m}^{2}$ was given for 2 days starting 1 day prior to each dose of FUDR. The $24 \mathrm{~h}$ infusions of gem citabine and FUDR were given through a central catheter using a portable infusion pump, whereas the 1 or $2 \mathrm{~h}$ infusions could be given through a peripheral vein if a central catheter was not yet available.

The dose of FUDR was escalated in new patient cohorts according to the degree of toxicity experienced at the prior dose level. If grade 1 toxicity (excluding nausea and vomiting) attrib utable to FUDR occurred in one or more patients, the FUDR dose was increased 2 fold. If grade 1 toxicity attributable to FUDR occurred in two patients or grade 2 toxicity occurred in one patient, the FUDR dose was increased 1.5 fold. If dose limiting toxicity occurred in one patient, two to five additional patients were to be entered at the same level. If dose limiting toxicity occurred in two patients, then this dose level was considered to exceed the maxi mum tolerated dose (MTD), and additional patients were entered at the preceding dose level. The recommended dose was defined as one dose level below that associated with dose limiting toxicity in two patients. Individual patients were allowed to escalate to the next dose of FUDR provided that nonhematologic toxicity was no more than grade 1 in severity and hematologic toxicity was no more than grade 2 in severity for the preceding two cycles. The 
FUDR dose was reduced if the patient experienced dose limiting toxicity or required a treatment interruption as described above for gemcitabine.

The treatment was resumed on day 28 if the absolute granu locyte count was $\geq 1500 / \mu \mathrm{l}$, the platelet count was $\geq 75,000 / \mu \mathrm{l}$ and all clinically significant nonhematologic toxicities had resolved. The dose of either gemcitabine or FUDR was altered based on the most severe toxicity. If clinical toxicity recurred during the subsequent cycle despite the prior dose reduction, the dose of the other drug was then decreased.

Patient evaluation and follow up

A history and physical examination, performance status assessment, complete blood count (CBC) and white blood cell (WBC) differ ential, blood urea nitrogen, creatinine, alanine aminotransferase (ALT), aspartate aminotransferase (AST), alkaline phosphatase, bilirubin, albumin, tumor markers and urinalysis were performed at the start of each cycle. CBC and WBC differential were done twice weekly. Radiographic scans needed for disease measurement per disease site were done pretreatment and every three cycles. Therapy was continued until there was evidence of disease progression as long as the patient agreed and the treatment was tolerated. A complete remission was defined as complete disappearance of all evidence of tumor and return of abnormal blood tests to normal levels for a minimum of 4 weeks. A partial response was a decrease by at least $50 \%$ in the sum of the products of the perpendicular diameters of all measured lesions in the absence of progression of any lesion or the appearance of any new lesions for at least 4 weeks. Stable disease was a change in measurable disease too small to meet the requirements for partial response or progression, provided there was no worsening of symptoms. Development of a new site of malignant disease or an increase $(>25 \%)$ in either the baseline measurements or those obtained at best response constituted disease progression. Toxicity was assessed using version 1 of the NCI Common Toxicity Criteria.

\section{Pharmacokinetic studies}

Blood was collected in $10 \mathrm{ml}$ draw heparinized tubes to which $10 \mathrm{nmol}$ tetrahydrouridine (Sigma, St. Louis, Mo.) had been added. The tubes were placed on ice immediately and centrifuged for $10 \mathrm{~min}$ at $800 \mathrm{~g}$; and the plasma was removed and stored at $-70^{\circ} \mathrm{C}$. Blood samples were taken during the infusions at the following time points: $24 \mathrm{~h}$ infusion, 22 and $23 \mathrm{~h} ; 2 \mathrm{~h}$ infusion, 90 and $105 \mathrm{~min}$; $1 \mathrm{~h}$ infusion, 30,40 and $50 \mathrm{~min}$.

$\mathrm{dFdU}$ was provided by Lilly Research Laboratories (India napolis, Ind.) through a material transfer agreement with the National Cancer Institute. The internal standard, 5' deoxy 5 fluorouridine ( $5^{\prime}$ DFUR), was obtained from Sigma (St. Louis, Mo.). Ammonium acetate was from Aldrich (Milwaukee, Wis.). HPLC grade water and methanol were from Fisher (Fair Lawn, N.J.). Tetrahydrouridine (lot no. $112907 \mathrm{~J} / 22$ ) was provided by the Drug Synthesis and Chemistry Branch at the National Cancer Institute (Bethesda, Md.). Pooled donor plasma was provided by the Department of Transfusion Medicine, Warren G. Magnusen Clinical Center, National Institutes of Health (Bethesda).

The plasma concentrations of gemcitabine and $\mathrm{dFdU}$ for the $1 \mathrm{~h}$ and $2 \mathrm{~h}$ infusions were analyzed using our validated reversed phase HPLC method with photodiode array detection as previ ously described [15]. Since the plasma levels for the $24 \mathrm{~h}$ infusion of gemcitabine were anticipated to be below the limit of detection for the HPLC assay, we developed a validated, liquid chroma tography method with mass selective detection [16]. After the addition of $250 \mathrm{ng} 5^{\prime}$ DFUR, a $0.5 \mathrm{ml}$ plasma sample was diluted with an equal volume of phosphate buffered saline (PBS, $1 \times$, $\mathrm{pH}$ 7.4). Solid phase extraction was performed using an Oasis HLB $3 \mathrm{ml}$ cartridge (Waters, Milford, Mass.) that had been conditioned with $3 \mathrm{ml}$ methanol and $3 \mathrm{ml}$ PBS. After loading the sample, the cartridge was washed with $2 \mathrm{ml}$ PBS, and the analytes were eluted with $2 \mathrm{ml}$ methanol. The eluate was evaporated to dryness and reconstituted in $0.5 \mathrm{ml}$ HPLC grade water. After vortex mixing, the solution was filtered through a GHP Acrodisc syringe filter (Pall Corporation, Ann Arbor, Mich.), then trans ferred to an autosampler vial. Separation was achieved with a YMC ODS AQ $(5 \mu \mathrm{m}, 120 \AA, 2.0 \times 150 \mathrm{~mm})$ column, obtained from Waters, preceded by a SecurityGuard C18 guard column (Phenomenex, Torrance, Calif.). A Waters 2960 separations module was set at $4{ }^{\circ} \mathrm{C}$; the column temperature was $30^{\circ} \mathrm{C}$.

The initial composition of the mobile phase was $2 \%$ methanol/ $98 \% 5 \mathrm{mM}$ ammonium acetate at $\mathrm{pH} 6.8(\mathrm{v} / \mathrm{v})$. An isocratic gradient was used at $0.2 \mathrm{ml} / \mathrm{min}$ for $3 \mathrm{~min}$, followed by a linear gradient over $4 \mathrm{~min}$ to $30 \%$ methanol $/ 70 \% 5 \mathrm{mM}$ ammonium acetate, $\mathrm{pH}$ 6.8. The gradient was returned to initial conditions over $2 \mathrm{~min}$ and remained there for $6 \mathrm{~min}$. The retention times of $\mathrm{dFdC}, \mathrm{dFdU}$ and $5^{\prime} \mathrm{DFUR}$ were $11.5,12.6$ and $13.6 \mathrm{~min}$. A Micromass Platform LC MS detector (from Waters) was operated in negative electrospray ionization mode. Single ion monitoring (SIM) mode was used for analyte quantitation at $\mathrm{m} / \mathrm{z} 262$ for $[\mathrm{dFdC} \mathrm{H}]^{-}, \mathrm{m} / \mathrm{z} 263$ for $[\mathrm{dFdU} \mathrm{H}]^{-}$, and $\mathrm{m} / \mathrm{z} 245$ for $\left[5^{\prime} \mathrm{DFUR}\right.$ $\mathrm{H}]^{-}$. The average recoveries for $\mathrm{dFdC}, \mathrm{dFdU}$, and $5^{\prime} \mathrm{DFUR}$ were $88.4 \%, 84.6 \%$, and $99.3 \%$, respectively. The linear calibration ranges were $51000 \mathrm{ng} / \mathrm{ml}$ for $\mathrm{dFdC}$, and $55000 \mathrm{ng} / \mathrm{ml}$ for $\mathrm{dFdU}$. The intra and interassay precisions $(\% \mathrm{CV})$ were $\leq 3 \%$ and $\leq 7 \%$ at three concentration levels $(50,500$, and $5000 \mathrm{ng} / \mathrm{ml})$. The limits of quantitation defined as ten times signal to noise ratios were $3.16 \mathrm{ng} / \mathrm{ml}$ for $\mathrm{dFdC}$ and $1.35 \mathrm{ng} / \mathrm{ml}$ for $\mathrm{dFdU}$.

The area under the curve was determined by noncompartmental methods using a continuous intravenous infusion model with WinNonLin 4.0 (Pharsight Corporation, Mountain View, Calif.) The graphs were prepared using SigmaPlot 8.02 for Windows (SPSS, Chicago, Ill.).

\section{Assessment of thymidylate synthase inhibition}

In patients who had not received prior pelvic radiation and were not receiving therapeutic anticoagulation, paired bone marrow aspirates were planned immediately prior to therapy and again at the end of the initial $24 \mathrm{~h}$ FUDR infusion. The samples were first passed through a $400 \mu \mathrm{m} 25 \mathrm{~mm}$ filter disc held in a Swinnex (Millipore) filter holder to remove bone spicules and fat globules. The mononuclear cells were isolated by Ficoll Hypaque density centrifugation; erythrocytes were removed with a brief hypotonic lysis step, and the intact cell pellet was stored at $-80^{\circ} \mathrm{C}$. On the day of analysis, a protease inhibitor cocktail was added to the pellets, the cell membranes were disrupted by sonication, and the lysate was isolated after centrifugation at $12,000 \mathrm{~g}$ for $15 \mathrm{~min}$ at $4{ }^{\circ} \mathrm{C}$. Equal amounts of protein $(50 \mu \mathrm{g})$ were resolved by $10 \%$ sodium dodecyl sulfate polyacrylamide gel electrophoresis as previously described [17].

\section{Results}

\section{Patients}

Entered into this trial were 42 adult patients (Table 1); $93 \%$ had no more than minor cancer-related symptoms. The majority had colorectal or pancreatic cancer, and patients had received a median of two prior chemotherapy regimens. Nine patients with no prior chemotherapy were added to the then current dose level to avoid delays in initiating therapy. Eight patients received a median of two cycles with a 24-h infusion of gemcitabine (range one to nine). Seven patients received a 2-h gemcitabine infusion; the median number of cycles was 
Table 1 Patient characteristics

\begin{tabular}{ll}
\hline Age (years) & \\
Median & 51 \\
Range & 2377 \\
Male/female & $22 / 20$ \\
Performance status & \\
0 & 15 \\
1 & 24 \\
2 & 3 \\
No. of patients with prior therapy & \\
Chemotherapy & 32 \\
Immunotherapy & 9 \\
Radiotherapy & 6 \\
No. of prior chemotherapy regimens & \\
Median & 2 \\
Range & 05 \\
Origin of primary tumor & \\
Colorectal & 13 \\
Pancreas & 10 \\
Lung & 6 \\
Appendix or small intestine & 3 \\
Unknown primary & 3 \\
Other & 7 \\
\hline
\end{tabular}

three (range one to six). Among 27 patients who received a 1-h gemcitabine infusion, a median of four cycles was given (range 1-21).

Clinical toxicity during the initial cycle with gemcitabine alone

Due to concern about interpatient differences in sensitivity to gemcitabine and the potential for additive toxicity with the addition of FUDR, gemcitabine was given alone in cycle 1 , and a conservative dose-modification scheme was adopted for gemcitabine. Table 2 presents the hematologic toxicities occurring during cycle 1 according to the dose and duration of gemcitabine infusion. With a 24-h infusion, none of three patients who received $150 \mathrm{mg} / \mathrm{m}^{2}$ could tolerate more than two weekly doses due to grade 2 mucositis and grade 3 fatigue (one patient) or grade 3 thrombocytopenia (two patients). In the interest of patient safety, the starting dose was decreased to $100 \mathrm{mg} / \mathrm{m}^{2}$ for the next five patients. One patient withdrew from the study after receiving a single dose; she experienced grade 1 nausea and lightheadedness, but felt that further side effects were unacceptable. Therapy was interrupted in another patient after one dose due to small-bowel obstruction requiring surgical bypass. One patient experienced grade 4 neutropenia after two doses of gemcitabine, but tolerated the subsequent cycle at a reduced dose of $60 \mathrm{mg} / \mathrm{m}^{2}$. Two patients who experienced grade 3 neutropenia after receiving all three weekly doses received a dose reduction to $80 \mathrm{mg} / \mathrm{m}^{2}$ for the second cycle.

Based on this experience, the toxicity associated with the 24-h infusion was deemed to be excessive. The protocol was amended to utilize a 2 -h infusion of $1000 \mathrm{mg} / \mathrm{m}^{2}$. Seven patients were enrolled. Four patients received only two doses of gemcitabine. In one, this was due to the onset of disease-related jaundice. Two of the four patients experienced grade 3 thrombocytopenia, and the dose of gemcitabine was decreased to $600 \mathrm{mg} / \mathrm{m}^{2}$ for the second cycle, and the other patient had grade 2 fatigue, fever and headache, but tolerated $800 \mathrm{mg} / \mathrm{m}^{2}$ the next cycle. Among three patients who got all three weekly doses, two required a dose reduction in the second cycle to $800 \mathrm{mg} / \mathrm{m}^{2}$ for grade 3 neutropenia and thrombocytopenia (one patient each).

Since only one patient tolerated the initial cycle with $1000 \mathrm{mg} / \mathrm{m}^{2}$ over $2 \mathrm{~h}$, the infusion duration was shortened to $1 \mathrm{~h}$. Of 27 patients, 2 had the cycle interrupted after a single dose of gemcitabine to allow either palliative radiation therapy to a preexisting left femoral metastasis, or biliary stenting for disease-related obstruction. In the second cycle, both tolerated all three doses without appreciable toxicity. Seven patients required termination of cycle 1 after two doses due to toxicity: grade 3 or 4 thrombocytopenia (two each), grade 4 neutropenia (two patients, one of whom also had grade 3 platelet toxicity and fatigue), and grade 2 diarrhea (one patient). Of 24 patients who received a second cycle of therapy, 11 received a gemcitabine dose reduction to either $800(n=5)$ or $600 \mathrm{mg} / \mathrm{m}^{2}(n=6)$.

\section{Clinical toxicity with the addition of FUDR}

Since initiation of FUDR was delayed until a tolerable dose of gemcitabine had been defined for each patient, a given dose level of FUDR might be administered with different gemcitabine doses. Additional patients

Table 2 Hematological toxicity cycle 1 with gemcitabine alone

\begin{tabular}{|c|c|c|c|c|c|c|c|c|}
\hline \multirow{3}{*}{$\begin{array}{l}\text { Infusion } \\
\text { duration (h) }\end{array}$} & \multirow{3}{*}{$\begin{array}{l}\text { Dose } \\
\left(\mathrm{mg} / \mathrm{m}^{2}\right)\end{array}$} & \multicolumn{2}{|c|}{ No. of patients } & \multirow{3}{*}{$\begin{array}{l}\text { WBC nadir } \\
(\times 1000 / \mu \mathrm{l}) \\
\text { Median } \\
\text { (range) }\end{array}$} & \multirow{3}{*}{$\begin{array}{l}\text { ANC nadir } \\
(/ \mu \mathrm{l}) \\
\text { Median } \\
\text { (range) }\end{array}$} & \multirow{3}{*}{$\begin{array}{l}\text { Platelet nadir } \\
(\times 1000 / \mu \mathrm{l}) \\
\begin{array}{l}\text { Median } \\
\text { (range) }\end{array}\end{array}$} & \multicolumn{2}{|c|}{ Hemoglobin $(\mathrm{g} / \mathrm{dl})$} \\
\hline & & Total & Receiving all three & & & & Nadir & \\
\hline & & & planned doses & & & & $\begin{array}{l}\text { Median } \\
\text { (range) }\end{array}$ & $\begin{array}{l}\text { Decrease from } \\
\text { baseline }\end{array}$ \\
\hline \multirow[t]{4}{*}{24} & 150 & 3 & 0 & $3.5(2.24 .0)$ & $2205(946 \quad 2436)$ & $24\left(\begin{array}{ll}16 & 26\end{array}\right)$ & $8.4\left(\begin{array}{ll}7.0 & 9.0\end{array}\right)$ & \multirow{4}{*}{$\begin{array}{l}-3.6(-3.9 \text { to }-0.9) \\
-2.5(-4.2 \text { to }-0.7) \\
-2.5(-5.4 \text { to }-1.3) \\
-2.1(-5.6 \text { to } 1.4)\end{array}$} \\
\hline & 100 & 5 & 2 & $1.6(1.26 .6)$ & $696(448$ 4897) & 85 (66 284) & $10.1(8$ 11.2) & \\
\hline & 1000 & 7 & 3 & $2.3\left(\begin{array}{lll}1.2 & 3.7\end{array}\right)$ & $1323(706 \quad 2134)$ & $50\left(\begin{array}{ll}33 & 147\end{array}\right)$ & $8.9\left(\begin{array}{lll}6.9 & 11.3\end{array}\right)$ & \\
\hline & 1000 & $25^{\mathrm{a}}$ & 19 & $2.4\left(\begin{array}{ll}0.5 & 7.2\end{array}\right)$ & $1166(2245054)$ & 108 (16 272) & $10(7.611 .4)$ & \\
\hline
\end{tabular}

${ }^{a}$ Two patients not included since therapy was interrupted after a single dose to permit palliative radiation therapy and biliary stent placement, rather than for treatment related toxicity 
Table 3 Dose escalation of FUDR (the data are presented according to dose rather than chronological order of patients)

\begin{tabular}{|c|c|c|c|c|}
\hline \multicolumn{2}{|c|}{ Gemcitabine } & \multirow[t]{2}{*}{ Patients } & \multirow{2}{*}{$\begin{array}{l}\text { FUDR } \\
\left(\mathrm{mg} / \mathrm{m}^{2}\right)\end{array}$} & \multirow{2}{*}{$\begin{array}{l}\text { Dose limiting toxicity } \\
\text { first cycle with FUDR? }\end{array}$} \\
\hline $\begin{array}{l}\text { Infusion } \\
\text { time (h) }\end{array}$ & $\begin{array}{l}\text { Dose } \\
\left(\mathrm{mg} / \mathrm{m}^{2}\right)\end{array}$ & & & \\
\hline \multirow[t]{4}{*}{24} & 100 & 1 & 5 & 0 \\
\hline & 80 & 1 & 5 & 0 \\
\hline & 60 & 1 & 5 & 0 \\
\hline & 80 & 1 & 10 & 0 \\
\hline \multirow[t]{3}{*}{2} & 1000 & 1 & 10 & 0 \\
\hline & 800 & 2 & 10 & 0 \\
\hline & 600 & 1 & 10 & 1 (grade 3 platelets) \\
\hline \multirow[t]{8}{*}{1} & 1000 & 3 & 10 & 0 \\
\hline & 1000 & 2 & 12.5 & 0 \\
\hline & 800 & 1 & 12.5 & 0 \\
\hline & 1000 & 5 & 15.6 & 0 \\
\hline & 1000 & 2 & 19.5 & 0 \\
\hline & 800 & 3 & 19.5 & 0 \\
\hline & 600 & 2 & 19.5 & 0 \\
\hline & 400 & 1 & 19.5 & 1 (grade 3 platelets) \\
\hline
\end{tabular}

Table 4 Toxicity during the initial cycle with FUDR and gemcit abine in 26 patients with paired cycles (one patient who received only one weekly dose of gemcitabine/FUDR due to new onset of obstructive jaundice is not included). Values are means \pm SD

\begin{tabular}{llll}
\hline & $\begin{array}{l}\text { Gemcitabine } \\
\text { alone }\end{array}$ & $\begin{array}{l}\text { Gemcitabine } \\
\text { plus FUDR }\end{array}$ & $\begin{array}{l}P \text { value } \\
\text { (paired } t \text { test) }\end{array}$ \\
\hline White blood cells $(/ \mu \mathrm{l})$ & $3385 \pm 1181$ & $3373 \pm 1050$ & 0.964 \\
Hemoglobin $(\mathrm{g} / \mathrm{dl})$ & $9.76 \pm 1.06$ & $9.35 \pm 1.01$ & 0.036 \\
Platelet $(1000 / \mu \mathrm{l})$ & $130 \pm 45$ & $122 \pm 61$ & 0.409 \\
Neutrophils $(/ \mu \mathrm{l})$ & $1896 \pm 951$ & $1849 \pm 749$ & 0.821 \\
\hline
\end{tabular}

Table 5 Numbers of patients with toxicity during the initial cycle with FUDR and gemcitabine

\begin{tabular}{llll}
\hline Toxicity & Grade & $\begin{array}{l}\text { Gemcitabine } \\
\text { alone }\end{array}$ & $\begin{array}{l}\text { Gemcitabine } \\
\text { plus FUDR }\end{array}$ \\
\hline Mucositis & 1 & 0 & 3 \\
Nausea/vomiting & 2 & 0 & 1 \\
& 1 & 15 & 7 \\
Diarrhea & 2 & 0 & 2 \\
Fatigue & 3 & 0 & 1 \\
& 1 & 2 & 3 \\
& 1 & 19 & 14 \\
\hline
\end{tabular}

were added to a given FUDR dose level if sufficient safety information did not permit escalation to the next dose level. As shown in Table 3, 27 patients received one or more cycles of gemcitabine with FUDR; four entry dose levels ranging from 5 to $19.5 \mathrm{mg} / \mathrm{m}^{2}$ over $24 \mathrm{~h}$ were explored. Dose-limiting thrombocytopenia was observed in one patient each at $10 \mathrm{mg} / \mathrm{m}^{2}$ and $19.5 \mathrm{mg} / \mathrm{m}^{2}$. The clinical toxicities during 26 matched cycles in which patients received the same dose of gemcitabine alone or with FUDR are compared in Tables 4 and 5. With the exception of anemia, there was no significant difference between the nadirs in the cycle without and with FUDR. Four patients (15.4\%) experienced grade 1 or 2 mucositis with the addition of FUDR (one at 10, two at 15.6 , and one at $19.5 \mathrm{mg} / \mathrm{m}^{2}$ ); none had mucositis during the preceding cycle with gemcitabine alone. Patients were allowed to escalate to the next dose level of FUDR if they had minimal toxicity the preceding two cycles, and the dose was decreased if needed. A total of 111 cycles with gemcitabine and FUDR were given.

When the worst grade of hematologic toxicity per patient per dose level was considered, no instances of grade 4 leukopenia, neutropenia or thrombocytopenia occurred. Grade 3 thrombocytopenia was observed as follows $\left(\mathrm{mg} / \mathrm{m}^{2}\right)$ : 5 , one of six patients; 10, two of nine patients; 12.5 , one of four patients; 15.6, none of eight patients; and 19.5, four of ten patients. Two patients who initially received $19.5 \mathrm{mg} / \mathrm{m}^{2}$ escalated to $24.5 \mathrm{mg} / \mathrm{m}^{2}$, and one of these had grade 3 thrombocytopenia during his third cycle at the higher dose. Prior to defining the MTD of FUDR, the pharmaceutical supplier provided notice of an impending shortage of the clinical formulation of FUDR; therefore, the trial was closed early.

Overall clinical toxicity in patients receiving 1-h gemcitabine alone or with FUDR

The worst toxicities experienced by each patient across all cycles of therapy in patients receiving gemcitabine over $1 \mathrm{~h}$ are shown in Table 6 . Hematologic toxicity predominated, with grade $3 / 4$ toxicities as follows: leukopenia $18.5 \%$, anemia $26 \%$, thrombocytopenia $30 \%$, and neutropenia $63 \%$. Two patients had Clostridium difficile-associated diarrhea of grade 3 severity, but both tolerated subsequent cycles at the same doses without problems. After completion of the FUDR infusion week 1 of cycle 5, a 72-year-old male with renal cell cancer received two units of packed red blood cells for symptomatic anemia (hemoglobin $8.5 \mathrm{~g} / \mathrm{dl}$ ). Later that evening he was admitted to his local hospital's intensive care unit for acute onset of shortness of breath requiring temporary intubation and aggressive diuresis; the serum creatinine was elevated at $2.2 \mathrm{mg} / \mathrm{dl}$. He recovered within a few days. Subsequent cardiac evaluation with an echocardiogram and a persantine/thallium scan were unremarkable. This episode of noncardiogenic pulmonary edema was considered possibly related to therapy, although transfusion-related acute lung injury may represent a plausible alternative. A 45-year-old male with adenocarcinoma of the appendix presented with hypertension when he returned for cycle 9. Work-up revealed hemolytic uremic syndrome on the basis of elevated creatinine, thrombocytopenia, microangiopathic hemolytic anemia, and pathognomonic findings on renal biopsy. He received intensive plasmapheresis and antihypertensive therapy, with stabilization of his renal function. No further protocol therapy was given to either patient. 
Table 6 Worst toxicity per patient receiving gemcitabine by $1 \mathrm{~h}$ infusion across all cycles of therapy (presented as the numbers of patients with a given toxicity among a total of 27 patients)

\begin{tabular}{lllll}
\hline Toxicity & Grade 1 & Grade 2 & Grade 3 & Grade 4 \\
\hline Leukopenia & 3 & 18 & 4 & 1 \\
Anemia & 7 & 13 & 6 & 1 \\
Thrombocytopenia & 12 & 7 & 6 & 2 \\
Neutropenia & 3 & 6 & 13 & 4 \\
Nausea/vomiting & 13 & 7 & 1 & 0 \\
Mucositis & 5 & 1 & 0 & 0 \\
Diarrhea & 7 & 1 & $2^{\mathrm{a}}$ & 0 \\
Fatigue & 17 & 7 & 2 & 0 \\
Skin & 13 & 2 & 0 & 0 \\
Fever & 4 & 14 & 0 & 0 \\
Anorexia & 12 & 0 & 0 & 0 \\
Myalgias & 8 & 1 & 0 & 0 \\
Headache & 9 & 0 & 0 & 0 \\
Alopecia & 8 & 1 & 0 & \\
Pulmonary & 4 & 2 & 0 & 1 \\
Hemolytic uremia & 0 & 0 & 0 & 1 \\
\hline
\end{tabular}

${ }^{\mathrm{a} C l o s t r i d i u m ~ d i f f i c i l e ~ a s s o c i a t e d ~}$

\section{Clinical outcome}

Measurable disease was not required for the study. Three patients were not assessable for response (withdrew from study after one cycle, two patients; evaluable but nonmeasurable disease, one patient). Of 39 patients assessable for response, 3 partial responses were seen (one patient with heavily pretreated breast cancer, and two previously untreated patients with adenocarcinoma of unknown primary and pancreatic cancer). All three received a 1-h gemcitabine infusion, and they remained on study for 262,666 , and 813 days, respectively. Of the remaining 36 patients assessable for response, 14 had stable disease lasting 3 months or longer, and 22 experienced disease progression within 3 months.

\section{Gemcitabine pharmacokinetics}

Pharmacokinetic sampling was performed in 55 cycles in 39 patients with adequate venous access. Figure 1 shows the plasma concentration $(\mathrm{Cp})$ of gemcitabine and $\mathrm{dFdU}$ during the initial infusion of $1000 \mathrm{mg} / \mathrm{m}^{2}$ gemcitabine according to duration of infusion. With the 2-h infusion, no difference was seen in the Cp between the 90-min and 105-min samples, indicating that steady-state had been achieved. With the 1-h infusion, there was a trend for the $\mathrm{Cp}$ at $50 \mathrm{~min}$ to be higher than the 30 -min value $(P=0.08)$, whereas there was no significant difference between the 40-min and 50-min values. For both infusion durations, the $\mathrm{Cp}$ of $\mathrm{dFdU}$ increased throughout the infusion. The $\mathrm{AUC}_{\text {last }}$ (mean $\pm \mathrm{SD}$ ) for gemcitabine for the 1-h $(n=23)$ and 2-h $(n=7)$ infusions were $947 \pm 283$ and $988 \pm 209 \mathrm{nmol} / \mathrm{ml} \cdot \mathrm{min}$, and for $\mathrm{dFdU}$ were $2670 \pm 682$ and $4704 \pm 1532 \mathrm{nmol} / \mathrm{ml} \cdot \mathrm{min}$. Figure 2 shows the maximum concentration (Cmax) values as a function of gemcitabine dose rate (total milligrams per minute). There was a strong correlation between dose rate and Cmax for both gemcitabine and $\mathrm{dFdU}$. If only

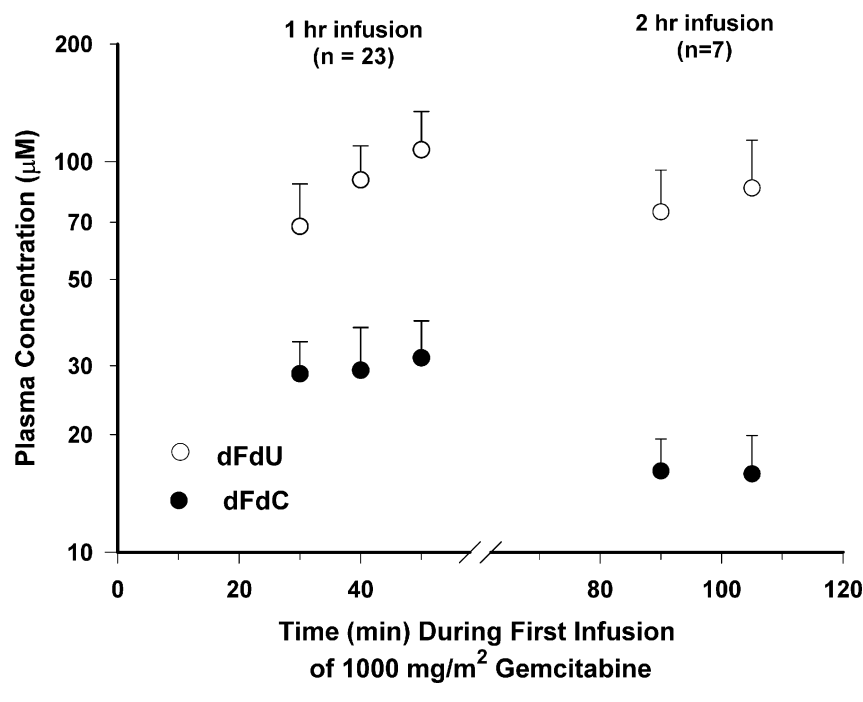

Fig. 1 Gemcitabine $(\mathrm{dFdC})$ and $2^{\prime}, 2^{\prime}$ difluorodeoxyuridine (dFdU) plasma levels during the initial infusion. The data for each time point are shown as the means $\pm \mathrm{SD}$

the data for the 1-h and 2-h infusions are considered (Fig. 2, inset), the correlation for gemcitabine was moderately strong $\left(r=0.582, P=3.45 \times 10^{8}\right)$, and there was no correlation for $\mathrm{dFdU}(r=0.23)$. The results were similar when dose rate expressed as milligrams per minute per meter squared was used (data not shown).

Plasma samples were obtained during weeks 1 and 3 in 31 cycles. There was no difference in the average $\mathrm{Cp}$ after either dose (1-h and 2-h combined): $23.81 \mu M$ versus $25.22 \mu M(P=0.18$, paired $t$-test $)$. The average $\mathrm{Cp}$ during the cycle (Table 7) for the 1-h infusion was 1.84-fold higher than that measured for the 2-h infusion, and the ratio of $\mathrm{dFdU}$ to gemcitabine was about threeand fivefold, respectively. For the 1-h and 2-h infusions, there was no appreciable difference in the $\mathrm{AUC}_{\text {last }}$ based on gender (median, 25th percentile, 75th percentile) for either gemcitabine [female, $1052 \mathrm{nmol} / \mathrm{ml} \cdot \mathrm{min}$ (888$1228 \mathrm{nmol} / \mathrm{ml} \cdot \mathrm{min}) ; \quad$ male, $947 \mathrm{nmol} / \mathrm{ml} \cdot \mathrm{min} \quad(840$ $1028 \mathrm{nmol} / \mathrm{ml} \cdot \mathrm{min} ; P=0.220$, rank sum test)] or $\mathrm{dFdU}$ [female, $3147 \mathrm{nmol} / \mathrm{ml} \cdot \mathrm{min} \quad(2958-3899 \mathrm{nmol} / \mathrm{ml} \cdot \mathrm{min})$; male, $2958 \mathrm{nmol} / \mathrm{ml} \cdot \mathrm{min}(2358-3230 \mathrm{nmol} / \mathrm{ml} \cdot \mathrm{min})]$.

With the 24-h infusion, the Cp for gemcitabine averaged $61 \mathrm{n} M$ and $50 \mathrm{n} M$ for 150 and $100 \mathrm{mg} / \mathrm{m}^{2}$, and the ratio of $\mathrm{dFdU}$ to gemcitabine was much greater than observed with the shorter infusions. Following the initial infusion of $150 \mathrm{mg} / \mathrm{m}^{2}(n=3)$ and $100 \mathrm{mg} / \mathrm{m}^{2}(n=4)$ gemcitabine, the $\mathrm{AUC}_{\text {last }}($ mean $\pm \mathrm{SD}$ ) for gemcitabine were $46 \pm 11$ and $39 \pm 22 \mathrm{nmol} / \mathrm{ml} \cdot \mathrm{min}$, and for $\mathrm{dFdU}$, the corresponding values were $7650 \pm 1513$ and $3468 \pm 1260 \mathrm{nmol} / \mathrm{ml} \cdot \mathrm{min}$. Clearance during the initial cycle was calculated by dividing the dose rate by the steady-state $\mathrm{Cp}$ (24-h and 2-h infusion); the median values were $5961 \mathrm{ml} / \mathrm{min} / \mathrm{m}^{2}(25 \% / 75 \%$ percentiles, $\left.3988 / 8703 \mathrm{ml} / \mathrm{min} / \mathrm{m}^{2}\right)$ and $2107 \mathrm{ml} / \mathrm{min} / \mathrm{m}^{2}(25 \% / 75 \%$ percentiles, $1722 / 2259 \mathrm{ml} / \mathrm{min} / \mathrm{m}^{2}$ ), respectively. Clearance for the 1-h infusion was estimated by dividing the dose rate by the average of the $40-\mathrm{min}$ and $50-\mathrm{min}$ 
Fig. 2 The maximum plasma concentrations (Cmax) of $\mathrm{dFdC}$ and $\mathrm{dFdU}$ achieved are plotted against the gemcitabine dose rate. The data are from 93 gemcitabine infusions given over $24 \mathrm{~h}(n=16), 2 \mathrm{~h}(n=18)$ or $1 \mathrm{~h}(n=57)$. The Pearson correlation coefficients are shown. Inset data for gemcitabine Cmax in patients receiving a $2 \mathrm{~h}$ or $1 \mathrm{~h}$ infusion

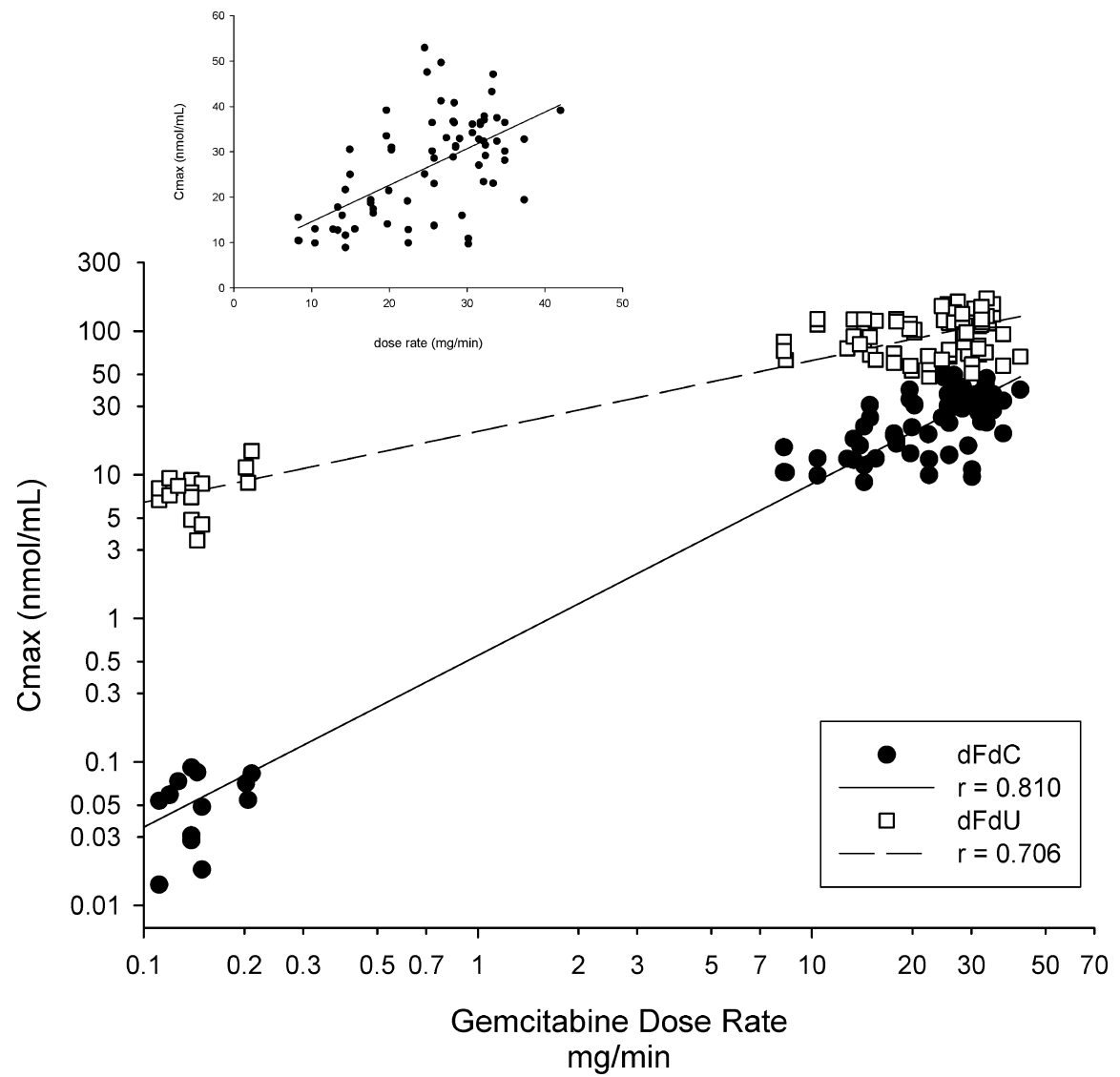

Table 7 Average gemcitabine and 2',2' difluorodeoxyuridine (dFdU) plasma concentrations. The average plasma concentrations at the various time points were calculated for each patient. If a patient had blood sampling during two infusions of a cycle, the results were averaged. Values are means $\pm \mathrm{SD}$

\begin{tabular}{llllll}
\hline Gemcitabine & & Number of patients & \multicolumn{2}{c}{ Plasma concentration $(\mu M)$} & Ratio dFdU to dFdC \\
\cline { 5 - 6 } Infusion duration $(\mathrm{h})$ & Dose $\left(\mathrm{mg} / \mathrm{m}^{2}\right)$ & & Gemcitabine & $\mathrm{dFdU}$ \\
\hline 1 & 1000 & 23 & 4 & $30.38 \pm 7.96$ & $86.75 \pm 22.39$ \\
& 800 & 4 & $24.76 \pm 8.37$ & $75.20 \pm 13.25$ & $3.2 \pm 0.9$ \\
& 600 & 1 & $18.75 \pm 7.65$ & $49.16 \pm 6.30$ & $3.1 \pm 0.8$ \\
2 & 400 & 7 & 23.8 & 57.15 & 2.4 \\
& 1000 & 2 & $16.32 \pm 3.36$ & $81.41 \pm 24.61$ & $5.1 \pm 1.5$ \\
24 & 800 & 3 & $11.38 \pm 1.22^{\mathrm{a}}$ & $67.95 \pm 5.45^{\mathrm{a}}$ & $6.0 \pm 0.1$ \\
& 600 & 5 & $0.061 \pm 0.012$ & $11.17 \pm 2.50$ & $188 \pm 18$ \\
& 150 & 2 & $0.0496 \pm 0.0231$ & $6.31 \pm 1.66$ & $166 \pm 86$ \\
& 100 & 1 & $0.0397 \pm 0.008^{\mathrm{a}}$ & $7.57 \pm 0.33^{\mathrm{a}}$ & $300 \pm 72^{\mathrm{a}}$ \\
\hline
\end{tabular}

\footnotetext{
${ }^{\mathrm{a}}$ Range $\times 0.5$
}

samples: the median was $2076 \mathrm{ml} / \mathrm{min} / \mathrm{m}^{2}(25 \% / 75 \%$ percentiles, $1833 / 2265 \mathrm{ml} / \mathrm{min} / \mathrm{m}^{2}$ ).

Patients with mild renal dysfunction (serum creatinine $<2.0 \mathrm{mg} / \mathrm{dl}$ ) were eligible for this protocol. The median baseline serum creatinine for all patients was $0.9 \mathrm{mg} / \mathrm{dl}$ (range $0.5-1.8 \mathrm{mg} / \mathrm{dl}$ ); only two patients had serum creatinine values above the upper limit of normal $(1.3 \mathrm{mg} / \mathrm{dl})$. To assess any potential effect of renal function on the pharmacokinetics of gemcitabine and $\mathrm{dFdU}$, the creatinine clearance for cycle 1 was estimated using the Cockcroft-Gault formula. The median value was $93 \mathrm{ml} / \mathrm{min}$ (range $32-179 \mathrm{ml} / \mathrm{min}$ ). Because the gemcitabine and $\mathrm{dFdU} \mathrm{AUC}_{\text {last }}$ for the 24-h infusion were significantly different from the values for the 1-h and 2-h infusions, the analysis was restricted to the two shorter infusions. If the data were analyzed by separating the values into two groups, i.e. the lowest third ( $\leq 75 \mathrm{ml} / \mathrm{min}, n=10$ ) versus the upper two-thirds ( $\geq 76 \mathrm{ml} / \mathrm{min}, n=20$ ), however, the $\mathrm{dFdU} \mathrm{AUC}_{\text {last }}$ appeared to be higher in those patients with lower estimated creatinine clearance values: median $(25 \mathrm{th} / 75$ th percentiles): $3421 \mathrm{nmol} / \mathrm{ml} \cdot \mathrm{min} \quad(3053 / 4465 \mathrm{nmol} / \mathrm{ml} \cdot \mathrm{min})$ 


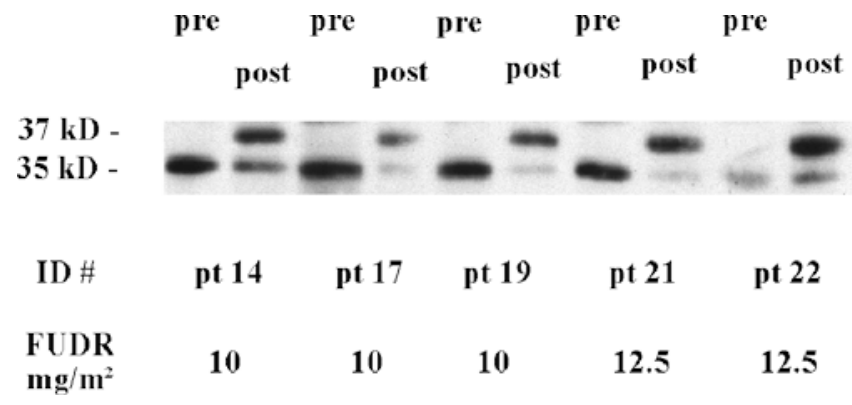

Fig. 3 Assessment of bound and free thymidylate synthase in paired bone marrow mononuclear cell samples obtained pre and during the FUDR infusion. The "pre" sample was obtained prior to receiving any protocol therapy; the "post" sample was taken at the end of the $24 \mathrm{~h}$ FUDR infusion

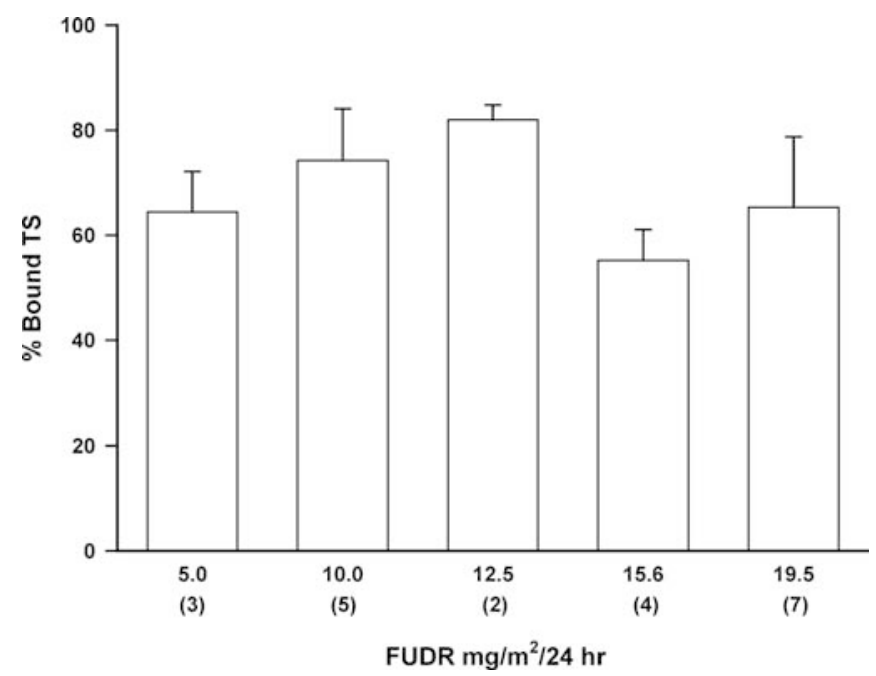

Fig. 4 Thymidylate synthase ternary complex formation in bone marrow mononuclear cells obtained at the end of the $24 \mathrm{~h}$ FUDR infusion. The number of patients is shown in parentheses. The data are shown as the mean $\pm \mathrm{SD}$ (or $1 / 2$ range if $n=2$ )

vs $2611 \mathrm{nmol} / \mathrm{ml} \cdot \min (21453191 \mathrm{nmol} / \mathrm{ml} \cdot \mathrm{min} ; P=0.019$, rank sum test). This is consistent with the differences in the mode of elimination between gemcitabine (metabolic) and $\mathrm{dFdU}$ (renal).

Possible pharmacodynamic relationships were explored for 35 patient-cycles for gemcitabine given as a 1 -h infusion (24 cycle 1,11 cycle 2 ). The median dose was $1000 \mathrm{mg} / \mathrm{m}^{2}$ (range $600-1000 \mathrm{mg} / \mathrm{m}^{2}$ ). There was no relationship between gemcitabine dose in milligrams (maximum $/$ minimum dose $=2.8$ ) and either the average gemcitabine $\mathrm{Cp}$ or the degree of hematologic toxicity (data not shown). For these cycles, the median $\mathrm{Cp}$ was $29.4 \mu M$ (range 9.5-44.2 $\mu M$ ). The average gemcitabine $\mathrm{Cp}$ did not correlate with the degree of hematologic toxicity (data not shown), suggesting that either the range of $\mathrm{Cp}$ was not great enough to permit pharmacodynamic correlates, or that other host factors play a greater role in determining hematologic toxicity.
Thymidylate synthase ternary complex formation during FUDR

Paired bone marrow aspirates were obtained from 21 patients prior to cycle 1 therapy and toward the end of the initial FUDR 24-h infusion. A representative immunoblot is shown in Fig. 3. In the pretherapy samples, a single band at $-35 \mathrm{kDa}$ representing unbound TS was seen. In the samples obtained during FUDR infusion, a slower migrating band at $-37 \mathrm{kDa}$ was evident that represents bound TS. The extent of ternary complex formation was not clearly different over the 3.9-fold dose range of FUDR (Fig. 4).

\section{Discussion}

With the current trial design, gemcitabine was given alone to establish a tolerable dose in each patient before the introduction of FUDR. A conservative dose modification scheme was used, such that the dose of gemcitabine was decreased for grade 3 and grade 2 hematologic and nonhematologic toxicity, respectively, or if all three weekly doses could not be given due to treatment-related toxicity. Although this strategy meant that different FUDR dose levels would be given with different gemcitabine doses, we felt that this design was in the best interests of patient safety. Further, the toxicity in the cycle in which FUDR was added could be compared to the prior cycle in which toxicity had been tolerable.

Gemcitabine displays exceptional schedule-dependent toxicity when given as a single agent. With a 6-h weekly infusion of gemcitabine for 3 of 4 weeks, the recommended dose is $250 \mathrm{mg} / \mathrm{m}^{2}\left(0.694 \mathrm{mg} / \mathrm{m}^{2}\right.$ per $\left.\min \right)$ [18]. Based on pharmacokinetic and cell cycle considerations along with preclinical data indicating that longer exposures to gemcitabine are more cytotoxic, a 24-h infusion has been explored in several trials, including the current one. Previously trials have led to recommended gemcitabine doses of either 100 or $150 \mathrm{mg} / \mathrm{m}^{2}[14,19]$. In the present study, we found that gemcitabine doses of 100 to $150 \mathrm{mg} / \mathrm{m}^{2}$ over $24 \mathrm{~h}\left(0.069\right.$ and $0.104 \mathrm{mg} / \mathrm{m}^{2}$ per min $)$ were poorly tolerated. This is the first report of the plasma concentrations of gemcitabine and $\mathrm{dFdU}$ achieved with a 24-h infusion schedule, accomplished through the development of a novel LC-MS assay. With 100 and $150 \mathrm{mg} / \mathrm{m}^{2}$, the gemcitabine steady-state $\mathrm{Cp}$ levels were in the 50-60 nM range. An apparent threefold increase in clearance was observed with the 24-h infusion. These results confirm that the MTD of gemcitabine decreases appreciably as the duration of infusion increases. We did not incorporate cellular pharmacology studies of gemcitabine, but assessment of dFdCTP formation might have proven informative. Development of nonradioisotopic methods to measure gemcitabine-DNA incorporation would surely provide an important investigative tool. 
Both the activation and deactivation of gemcitabine are saturable. Pharmacodynamic studies in patients indicate that the formation of $\mathrm{dFdCTP}$ in mononuclear cells reaches a plateau at $20 \mu M$, and a dose-rate of $10 \mathrm{mg} / \mathrm{m}^{2}$ per min has been proposed to avoid saturation of deoxycytidine kinase $[8,9,20]$. Following several dose-finding trials using this infusion rate, a total dose of $1500 \mathrm{mg} / \mathrm{m}^{2}$ has been recommended [21, 22, 23]. In one phase I trial in which 27 patients were treated with 1200 , 1500 or $1800 \mathrm{mg} / \mathrm{m}^{2}$ gemcitabine given over $2-3 \mathrm{~h}$, incidences of grade $3 / 4$ neutropenia and thrombocytopenia of $58 \%$ and $27 \%$, respectively, were found [21]. In another trial, grade 4 neutropenia and grade $3 / 4$ thrombocytopenia each occurred during the initial cycle at $1500 \mathrm{mg} / \mathrm{m}^{2}$ over $150 \mathrm{~min}$ in $37.5 \%$ of patients. When all cycles at this dose were considered, $27 \%$ and $58 \%$ of cycles were complicated by these degrees of toxicity, respectively [22]. Mani et al. reported grade $3 / 4$ neutropenia in $40 \%$ of patients receiving $10 \mathrm{mg} / \mathrm{m}^{2}$ per min for $150 \mathrm{~min}$ [23]. In our trial, only three of six assessable patients received all three planned gemcitabine doses during the initial cycle of $1000 \mathrm{mg} / \mathrm{m}^{2}$ over $2 \mathrm{~h}\left(8.3 \mathrm{mg} / \mathrm{m}^{2}\right.$ per $\left.\mathrm{min}\right)$, and two of these required dose reductions for their second cycle. We therefore explored a 1 -h infusion of $100 \mathrm{mg} / \mathrm{m}^{2}$ gemcitabine $\left(16.67 \mathrm{mg} / \mathrm{m}^{2}\right.$ per min). Due to the small number of patients, and the differences in dose modification schemes, it is not possible to comment on whether our results with the 2-h infusion are truly at odds with those reported in the literature for the $10 \mathrm{mg} / \mathrm{m}^{2}$ per min infusion strategy. With gemcitabine given as a 1-h infusion, 18 of 25 assessable patients $(72 \%)$ treated with $1000 \mathrm{mg} / \mathrm{m}^{2}$ were able to receive all three planned doses during their initial cycle, but five of these received a dose reduction of gemcitabine for cycle two.

We selected a continuous infusion of FUDR given over $24 \mathrm{~h}$ based on our preclinical data. Although FUDR is primarily used for regional therapy, there is clinical experience with continuous intravenous infusion $[24,25,26,27]$. The daily dose of FUDR given for 14 of 28 days in the intravenous arm of several randomized clinical trials comparing systemic with hepatic arterial infusion was $5.6 \mathrm{mg} / \mathrm{m}^{2}(0.15 \mathrm{mg} / \mathrm{kg})$ $[25,26,27]$; diarrhea was dose-limiting. The addition of low-dose leucovorin $\left(5 \mathrm{mg} / \mathrm{m}^{2}\right.$ per day) reduced the recommended dose of FUDR by $50 \%$ [28]. FUDR $28-37 \mathrm{mg} / \mathrm{m}^{2}$ per day was recommended for a 5- to 7day continuous infusion; mucositis and diarrhea were dose-limiting [29]. The addition of high-dose oral leucovorin reduced the recommended dose of FUDR to $11 \mathrm{mg} / \mathrm{m}^{2}$ per day for 5 days, and myelosuppression became dose limiting [30]. Since there was no published experience with FUDR given as a weekly 24-h infusion when this protocol was designed, a conservative starting dose of $5 \mathrm{mg} / \mathrm{m}^{2}$ was selected. In 26 matched cycles in which FUDR was added to the same dose of gemcitabine, there was no evidence of increased myelosuppression, diarrhea, nausea/vomiting, or fatigue, but there was a trend for a greater incidence of mucositis. Although we were unable to define the MTD of FUDR due to drug supply issues, we documented ternary complex formation of the target enzyme during the FUDR infusion despite the low doses of FUDR and leucovorin that were used. Measurement of TS catalytic activity is an alternative to immunoblot techniques, but requires the use of a radioisotope, and can be insensitive in detecting inhibition of the enzyme if the basal enzyme activity is low.

\section{References}

1. Garcia Carbinero R, Ryan DP, Chabner BA (2001) Cytidine analogs. In: Chabner BA, Longo DL (eds) Cancer chemo therapy and biotherapy: principles and practice, 3rd edn. Lip pincott Williams \& Wilkins, Philadelphia, p 255

2. Grem JL (2001) 5 Fluoropyrimidines. In: Chabner BA, Longo DL (eds) Cancer chemotherapy and biotherapy: principles and practice, 3rd edn. Lippincott Williams \& Wilkins, Philadelphia, p 185

3. Grem JL, Allegra CJ (1991) Sequence dependent interaction of 5 fluorouracil and arabinosyl 5 azacytosine or 1 beta D arabi nofuranosylcytosine. Biochem Pharmacol 42:409

4. Ren Q, Kao V, Grem JL (1998) Cytotoxicity and DNA frag mentation associated with sequential gemcitabine and 5 fluoro $2^{\prime}$ deoxyuridine in HT 29 colon cancer cells. Clin Cancer Res 4:2811

5. Rothenberg ML, Moore MJ, Cripps MC, Andersen JS, Portenoy RK, Burris HA, Green MR, Tarassoff PG, Brown TD, Casper ES, Storniolo AM, Von Hoff DD (1996) A phase II trial of gemcitabine in patients with $5 \mathrm{FU}$ refractory pancreas cancer. Ann Oncol 7:347

6. Ruiz van Haperen VWT, Veerman G, Boven E, Noordhuis P, Vermorken JB, Peters GJ (1994) Schedule dependence of sensitivity to $2^{\prime}, 2^{\prime}$ difluorodeoxycytidine (gemcitabine) in relation to accumulation and retention of its triphosphate in solid tumour cell lines and solid tumours. Biochem Pharmacol 48:1327

7. Veerman G, Ruiz van Haperen VW, Vermorken JB, Noordhuis P, Braakhuis BJ, Pinedo HM, Peters G (1996) Antitumor activity of prolonged as compared with bolus administration of $2^{\prime}, 2^{\prime}$ difluorodeoxycytidine in vivo against murine colon tumors. Cancer Chemother Pharmacol 38:335

8. Grunewald R, Abbruzzese JL, Tarassoff P, Plunkett W (1991) Saturation of $2^{\prime}, 2^{\prime}$ difluorodeoxycytidine $5^{\prime}$ tri phosphate accumulation by mononuclear cells during a phase I trial of gemcitabine. Cancer Chemother Pharmacol $27: 258$

9. Abbruzzese JL, Grunewald R, Weeks EA, Gravel D, Adams T, Nowak B, Mineishi S, Tarassoff P, Satterlee W, Raber MN, Plunkett W (1991) A phase I clinical, plasma, and cellular pharmacology study of gemcitabine. J Clin Oncol 9:491

10. Meta Analysis Group In Cancer (1998) Toxicity of fluoro uracil in patients with advanced colorectal cancer. Effect of administration schedule and prognostic factors. J Clin Oncol $16: 3537$

11. Meta analysis Group In Cancer (1998) Efficacy of intravenous continuous infusion of fluorouracil compared with bolus administration in advanced colorectal cancer. J Clin Oncol $16: 301$

12. de Gramont A, Bosset JF, Milan C, Rougier P, Bouché O, Etienne P L, Morvan F, Louvet C, Guillot T, Grancois E, Bedenne L (1997) Randomized trial comparing monthly low dose leucovorin and fluorouracil bolus with bimonthly high dose leucovorin and fluorouracil bolus plus continuous infusion for advanced colorectal cancer: a French intergroup study. J Clin Oncol 15:808 
13. Schmoll HJ, Köhne CH, Lorenz M, Schöffski P, Voigtmann R, Bokemeyer C, Lutz MP, Kleeberg U, Ridwelski K, Souchon R, El Sarafi M, Weiss U, Couvreur ML, Baron B, Wils JA (2000) Weekly $24 \mathrm{~h}$ infusion of high dose 5 fluorouracil with or without folinic acid vs. bolus $5 \mathrm{FU} /$ folinic acid (NCCTG/ Mayo) in advanced colorectal cancer: a randomized phase III study of the EORTC, GITCCG, and the AIO. Proc Am Soc Clin Oncol 19:A935

14. Anderson H, Thatcher N, Walling J, Hansen H (1996) A phase I study of a 24 hour infusion of gemcitabine in previously untreated patients with inoperable non small cell lung cancer. Br J Cancer 74:460

15. Keith B, Xu Y, Grem JL (2003) Measurement of the anti cancer agent gemcitabine in human plasma by high perfor mance liquid chromatography. J Chromatogr B 785:65

16. Xu Y, Keith B, Grem JL (2003) Measurement of gemcitabine and its deaminated metabolite at low concentrations in human plasma by liquid chromatography/mass spectrometry (abstract 5346). Proc Am Assoc Cancer Res 44:1224

17. Ren Q F, Van Groeningen CJ, Geoffroy F, Allegra CJ, John ston PG, Grem JL (1997) Determinants of cytotoxicity with prolonged exposure to fluorouracil in human colon cancer cells. Oncol Res 9:77

18. Akrivakis K, Schmid P, Flath B, Schweigert M, Sezer O, Mergenthaler HG, Possinger K (1999) Prolonged infusion of gemcitabine in stage IV breast cancer: a phase I study. Anti cancer Drugs 10:525

19. Eckel F, Lersch C, Assmann G, Schulte Frohlinde E (2002) Toxicity of a 24 hour infusion of gemcitabine in biliary tract and pancreatic cancer: a pilot study. Cancer Invest 20:180

20. Grunewald R, Kantarjian H, Du M, Faucher K, Tarassoff P, Plunkett W (1992) Gemcitabine in leukemia: a phase 1 clini cal, plasma, and cellular pharmacology study. J Clin Oncol 10:406

21. Brand R, Capadano M, Tempero M (1997) A phase I trial of weekly gemcitabine administered as a prolonged infusion in patients with pancreatic cancer and other solid tumors. Invest New Drugs 15:331 341
22. Touroutoglou N, Gravel D, Raber MN, Plunkett W, Abbruzzese JL (1998) Clinical results of a pharmacodynami cally based strategy for higher dosing of gemcitabine in patients with solid tumors. Ann Oncol 9:1003

23. Mani S, Kugler JW, Knost JA, Sciortino DF, Gibbons J, Garcia JC, Ansari RH, Schilsky RL, Vokes EE (1998) Phase II trial of 150 minute weekly infusion of gemcitabine in advanced colorectal cancer: minimal activity in colorectal cancer. Invest New Drugs 16:275

24. Lokich JJ, Sonneborn H, Paul S, Zipoli T (1983) Phase I study of continuous infusion of floxuridine chemotherapy. Cancer Treat Rep 67:791 793

25. Kemeny N, Daly J, Reichman B, Geller N, Botet J, Oderman P (1987) Intrahepatic or systemic infusion of fluorodeoxyuridine in patients with liver metastases from colorectal carcinoma. Ann Intern Med 107:459 465

26. Hohn DC, Stagg RJ, Friedman MA, Hannigan JF Jr, Rayner A, Ignoffo RJ, Acord P, Lewis BJ (1989) A randomized trial of continuous intravenous versus hepatic intraarterial floxuridine in patients with colorectal cancer metastatic to the liver: the Northern California Oncology Group trial. J Clin Oncol 7:1646 1654

27. Chang AE, Schneider PD, Sugarbaker PH, Simpson C, Culn ane M, Steinberg SM (1987) A prospective randomized trial of regional versus systemic continuous 5 fluorodeoxyuridine chemotherapy in the treatment of colorectal liver metastases. Ann Surg 206:685 693

28. Anderson N, Lokich J, Bern M, Wallach S, Moore C, Williams D (1989) A phase I clinical trial of combined fluoropyrimidines with leucovorin in a 14 day infusion. Demonstration of biochemical modulation. Cancer 63:233 237

29. Sullivan RD, Miller E (1965) The clinical effects of prolonged intravenous infusion of 5 fluoro $2^{\prime}$ deoxyuridine. Cancer Res 25:1025 1030

30. Vokes EE, Raschko JW, Vogelzang NJ, Warfield EE, Ratain MJ, Doroshow JH, Schilsky RL (1991) Five day infusion of fluorodeoxyuridine with high dose oral leucovorin: a phase I study. Cancer Chemother Pharmacol 28:69 73 